\title{
The Relationship between Two Kinds of Generalized Convex Set-Valued Maps in Real Ordered Linear Spaces
}

\author{
Zhi-Ang Zhou \\ College of Mathematics and Statistics, Chongqing University of Technology, Chongqing 400054, China \\ Correspondence should be addressed to Zhi-Ang Zhou; zhi_ang@163.com
}

Received 12 March 2013; Accepted 14 May 2013

Academic Editor: Graziano Crasta

Copyright (c) 2013 Zhi-Ang Zhou. This is an open access article distributed under the Creative Commons Attribution License, which permits unrestricted use, distribution, and reproduction in any medium, provided the original work is properly cited.

\begin{abstract}
A new notion of the ic-cone convexlike set-valued map characterized by the algebraic interior and the vector closure is introduced in real ordered linear spaces. The relationship between the ic-cone convexlike set-valued map and the nearly cone subconvexlike set-valued map is established. The results in this paper generalize some known results in the literature from locally convex spaces to linear spaces.
\end{abstract}

\section{Introduction}

In optimization theory, the generalized convexity of setvalued maps plays an important role. Corley [1] introduced the cone convexity of set-valued maps. To extend the cone convexity of set-valued maps, some authors [2-5] introduced new generalized convexity such as cone convexlikeness, cone subconvexlikeness, generalized cone subconvexlikeness, nearly cone subconvexlikeness, and ic-cone-convexlikeness. The above generalized convexity set-valued maps mentioned were defined in topological spaces. Recently, $\mathrm{Li}$ [6] has introduced the cone subconvexlike set-valued map based on the algebraic interior in linear spaces. Very recently, Hernández et al. [7] have defined the cone subconvexlikeness of the set-valued map characterized by the relative algebraic interior. $\mathrm{Xu}$ and Song [8] gave the relationship between iccone convexity and nearly cone subconvexlikeness in locally convex spaces. In this paper, we will extend the results obtained by $\mathrm{Xu}$ and Song [8] from locally convex spaces to linear spaces.

This paper is organized as follows. In Section 2, we give some preliminaries, including notations and lemmas. In Section 3, we obtain the relationship between ic-cone convexity and nearly cone subconvexlikeness in linear spaces. Our results generalize and improve the ones obtained by $\mathrm{Xu}$ and Song [8].

\section{Preliminaries}

In this paper, we always suppose that $A$ is a nonempty set and $Y$ is a real ordered linear space. Let 0 denote the zero element for every space. Let $K$ be a nonempty subset in $Y$. The affine hull of $K$ is defined as aff $(K):=\left\{k \mid k=\sum_{i=1}^{n} \lambda_{i} k_{i}, \forall i \epsilon\right.$ $\left.\{1,2, \ldots, n\}, k_{i} \in K, \lambda_{i} \in \mathbb{R}, \sum_{i=1}^{n} \lambda_{i}=1\right\}$. The generated cone of $K$ is defined as cone $(K):=\{\lambda k \mid k \in K, \lambda \geq 0\}$. Write cone ${ }_{+}(K):=\{\lambda k \mid k \in K, \lambda>0\}$. Clearly, cone $(K)=$ cone $_{+}(K) \cup\{0\} . K$ is called a cone if and only if $\lambda K \subseteq K$ for any $\lambda \geq 0$. Note that some authors defined the cone in the following way: $K$ is called a cone if and only if $\lambda K \subseteq K$ for any $\lambda>0$ [5]. It is possible that $0 \notin K$ if $K$ is a cone in the sense of the latter definition. Moreover, if $K$ is a cone in the sense of the latter definition, then $K \cup\{0\}$ is a cone in the sense of the former definition. In this paper, if not specially specified, we suppose that all the cones mentioned are defined in the sense of the former definition. $K$ is called a convex set if and only if

$$
\lambda k_{1}+(1-\lambda) k_{2} \in K, \quad \forall \lambda \in[0,1], \forall k_{1}, k_{2} \in K
$$

Clearly, a cone $K$ is convex if and only if $K+K \subseteq K . K$ is said to be nontrivial if and only if $K \neq\{0\}$ and $K \neq Y$.

From now on, we suppose that $C$ is a nontrivial convex cone in $Y$ and $C_{+}$satisfies the condition $C=C_{+} \cup\{0\}$. We recall the following well-known concepts. 
Definition 1 (see [9]). Let $K$ be a nonempty subset in $Y$. The algebraic interior of $K$ is the set

$$
\begin{gathered}
\operatorname{cor}(K):=\left\{k \in K \mid \forall h \in Y, \exists \lambda^{\prime}>0, \forall \lambda \in\left[0, \lambda^{\prime}\right],\right. \\
k+\lambda h \in K\} .
\end{gathered}
$$

Definition 2 (see [10]). Let $K$ be a nonempty subset in $Y$. The relative algebraic interior of $K$ is the set

$$
\begin{gathered}
\operatorname{icr}(K):=\left\{k \in K \mid \forall h \in \text { aff }(K)-k, \exists \lambda^{\prime}>0, \forall \lambda \in\left[0, \lambda^{\prime}\right],\right. \\
k+\lambda h \in K\} .
\end{gathered}
$$

Remark 3. Clearly, $\operatorname{cor}(K) \subseteq \operatorname{icr}(K)$. Moreover, if $\operatorname{cor}(K) \neq \emptyset$, then $\operatorname{cor}(K)=\operatorname{icr}(K)$.

Definition 4 (see [11]). Let $K$ be a nonempty subset in $Y$. The vector closure of $K$ is the set

$$
\begin{gathered}
\left.\operatorname{vcl}(K):=\left\{k \in Y \mid \exists h \in Y, \forall \lambda^{\prime}>0, \exists \lambda \in\right] 0, \lambda^{\prime}\right], \\
k+\lambda h \in K\} .
\end{gathered}
$$

Let $F: A \rightrightarrows Y$ be a set-valued map on $A . F(A):=$ $\bigcup_{x \in A} F(x)$.

Definition 5 (see [12]). A set-valued map $F: A \rightrightarrows Y$ is called nearly $C$-subconvexlike on $A$ if and only if $\operatorname{vcl}(\operatorname{cone}(F(A)+$ $C)$ ) is a convex set in $Y$.

Remark 6. When the set-valued map $F: A \rightrightarrows Y$ becomes a vector-valued map $f: A \rightarrow Y$, Definition 5 reduces to Definition 4.1 in [13]. When the linear spaces $Y$ becomes a topological space, Definition 5 becomes Definition 2.2 in [4].

In locally convex spaces, Sach [5] introduced the ic- $C_{+}{ }^{-}$ convexlikeness of the set-valued map. Now, we use the vector closure and the algebraic interior to introduce the ic- $C_{+}-$ convexlikeness of the set-valued map in linear spaces.

Definition 7. A set-valued map $F: A \rightrightarrows Y$ is called ic- $C_{+}-$ convexlike on $A$ if and only if cor $\left(\operatorname{cone}_{+}\left(F(A)+C_{+}\right)\right)$is a convex set in $Y$ and cone $e_{+}\left(F(A)+C_{+}\right) \subseteq \operatorname{vcl}\left(\operatorname{cor}\left(\right.\right.$ cone $_{+}(F(A)+$ $\left.\left.C_{+}\right)\right)$).

Lemma 8. Let $U_{1}$ and $U_{2}$ be two nonempty sets in $Y$. Then, $\operatorname{vcl}\left(U_{1} \cup U_{2}\right)=\operatorname{vcl}\left(U_{1}\right) \cup \operatorname{vcl}\left(U_{2}\right)$.

Proof. Since $U_{1} \subseteq U_{1} \cup U_{2}$ and $U_{2} \subseteq U_{1} \cup U_{2}, \operatorname{vcl}\left(U_{1}\right) \cup$ $\operatorname{vcl}\left(U_{2}\right) \subseteq \operatorname{vcl}\left(U_{1} \cup U_{2}\right)$. Now, we prove

$$
\operatorname{vcl}\left(U_{1} \cup U_{2}\right) \subseteq \operatorname{vcl}\left(U_{1}\right) \cup \operatorname{vcl}\left(U_{2}\right)
$$

Suppose that $y \notin \operatorname{vcl}\left(U_{1}\right) \cup \operatorname{vcl}\left(U_{2}\right)$. Then, $y \notin \operatorname{vcl}\left(U_{1}\right)$ and $y \notin$ $\operatorname{vcl}\left(U_{2}\right)$. For any $h \in Y$, there exists $\lambda_{1}>0$ such that

$$
\left.\left.y+\lambda h \notin U_{1}, \quad \forall \lambda \in\right] 0, \lambda_{1}\right] .
$$

For the above $h \in Y$, there exists $\lambda_{2}>0$ such that

$$
\left.\left.y+\lambda h \notin U_{2}, \quad \forall \lambda \in\right] 0, \lambda_{2}\right] .
$$

It follows from (6) and (7) that, for the above $h \in Y$, there exists $\lambda_{3}=\min \left\{\lambda_{1}, \lambda_{2}\right\}>0$ such that

$$
\left.\left.y+\lambda h \notin U_{1} \cup U_{2}, \quad \forall \lambda \in\right] 0, \lambda_{3}\right],
$$

which implies that $y \notin \operatorname{vcl}\left(U_{1} \cup U_{2}\right)$. Therefore, (5) holds. Thus, we obtain $\operatorname{vcl}\left(U_{1} \cup U_{2}\right)=\operatorname{vcl}\left(U_{1}\right) \cup \operatorname{vcl}\left(U_{2}\right)$.

Lemma 9 (see [11]). If $K$ is a nonempty convex set in $Y$ and $\operatorname{icr}(K) \neq \emptyset$, then
(a) $\operatorname{vcl}(K)$ is a convex set in $Y$;
(b) $\operatorname{vcl}(\operatorname{vcl}(K))=\operatorname{vcl}(K)$, namely, $v c l(K)$ is vectorially closed;
(c) $\operatorname{vcl}(K)=\operatorname{vcl}(i c r(K))$.

Lemma 10 (see [11]). Let $K$ be a nonempty subset of $Y$, and let $C$ be a nontrivial and convex cone with $\operatorname{cor}(C) \neq \emptyset$. Then, $\operatorname{cor}(K+\operatorname{cor}(C))=K+\operatorname{cor}(C)=\operatorname{cor}(v c l(K+C))=\operatorname{cor}(K+C)$.

Remark 11. The conclusions of Lemma 10 are true when $C$ is replaced by $C_{+}$.

\section{The Relationship between Two Kinds of Generalized Convexity}

In this section, we will give the relationship between two kinds of generalized convexity in real ordered linear spaces.

Theorem 12. Let $F: A \rightrightarrows Y$ be a set-valued map on $A$ and $i c r\left(\operatorname{cor}\left(\right.\right.$ cone $\left.\left._{+}\left(F(A)+C_{+}\right)\right)\right) \neq \emptyset$. If $F$ is ic- $C_{+}$-convexlike on $A$, then $F$ is nearly $C$-subconvexlike on $A$.

Proof. Since $F$ is ic- $C_{+}$-convexlike on $A$, cor $\left(\right.$ cone $_{+}(F(A)+$ $\left.C_{+}\right)$) is a convex set in $Y$ and cone $_{+}\left(F(A)+C_{+}\right) \subseteq$ $\operatorname{vcl}\left(\operatorname{cor}\left(\right.\right.$ cone $\left.\left._{+}\left(F(A)+C_{+}\right)\right)\right)$, which implies that

$$
\begin{aligned}
& \operatorname{vcl}\left(\operatorname{cone}_{+}\left(F(A)+C_{+}\right)\right) \\
& \quad \subseteq \operatorname{vcl}\left(\operatorname{vcl}\left(\operatorname{cor}\left(\operatorname{cone}_{+}\left(F(A)+C_{+}\right)\right)\right)\right) .
\end{aligned}
$$

Using the convexity of $\operatorname{cor}\left(\right.$ cone $\left._{+}\left(F(A)+C_{+}\right)\right)$and (b) of Lemma 9, we have

$$
\begin{aligned}
& \operatorname{vcl}\left(\operatorname{vcl}\left(\operatorname{cor}\left(\operatorname{cone}_{+}\left(F(A)+C_{+}\right)\right)\right)\right) \\
& \quad=\operatorname{vcl}\left(\operatorname{cor}\left(\operatorname{cone}_{+}\left(F(A)+C_{+}\right)\right)\right) .
\end{aligned}
$$

It follows from (9) and (10) that

$$
\operatorname{vcl}\left(\text { cone }_{+}\left(F(A)+C_{+}\right)\right) \subseteq \operatorname{vcl}\left(\operatorname{cor}\left(\text { cone }_{+}\left(F(A)+C_{+}\right)\right)\right) \text {. }
$$

Clearly,

$$
\operatorname{vcl}\left(\operatorname{cor}\left(\operatorname{cone}_{+}\left(F(A)+C_{+}\right)\right)\right) \subseteq \operatorname{vcl}\left(\text { cone }_{+}\left(F(A)+C_{+}\right)\right) .
$$


By (11) and (12), we obtain

$$
\operatorname{vcl}\left(\text { cone }_{+}\left(F(A)+C_{+}\right)\right)=\operatorname{vcl}\left(\operatorname{cor}\left(\text { cone }_{+}\left(F(A)+C_{+}\right)\right)\right) \text {. }
$$

Since cor $\left(\right.$ cone $\left._{+}\left(F(A)+C_{+}\right)\right)$is a convex set in $Y$, it follows from (13) and (a) of Lemma 9 that $\operatorname{vcl}\left(\right.$ cone $\left._{+}\left(F(A)+C_{+}\right)\right)$is a convex set in $Y$. Using Lemma 8, we have

$$
\begin{aligned}
\operatorname{vcl}(\operatorname{cone}(F(A)+C)) \\
=\operatorname{vcl}\left(\text { cone }_{+}(F(A)+C) \cup\{0\}\right) \\
=\operatorname{vcl}\left(\text { cone }_{+}(F(A)+C)\right) \cup \operatorname{vcl}\{0\} \\
=\operatorname{vcl}\left(\text { cone }_{+}(F(A)+C)\right) \\
=\operatorname{vcl}\left(\text { cone }_{+}(F(A))+C\right) \\
=\operatorname{vcl}\left(\text { cone }_{+}(F(A))+C_{+} \cup\{0\}\right) \\
=\operatorname{vcl}\left(\left(\text { cone }_{+}(F(A))+C_{+}\right) \cup \operatorname{cone}{ }_{+}(F(A))\right) \\
=\operatorname{vcl}\left(\text { cone }_{+}(F(A))+C_{+}\right) \cup \operatorname{vcl}\left(\operatorname{cone}_{+}(F(A))\right) .
\end{aligned}
$$

Now, we prove that

$$
\operatorname{vcl}\left(\text { cone }_{+}(F(A))\right) \subseteq \operatorname{vcl}\left(\text { cone }_{+}(F(A))+C_{+}\right) .
$$

Let $y \in \operatorname{vcl}\left(\right.$ cone $\left._{+}(F(A))\right)$. Then, $\exists h \in Y$, for all $\lambda^{\prime}>0, \exists \lambda \in$ $\left.10, \lambda^{\prime}\right]$, and we have

$$
y+\lambda h \in \text { cone }_{+}(F(A)) .
$$

Take $c \in C_{+}$in $Y$. By (16), $\exists h+c \in Y$, for all $\lambda^{\prime}>0, \exists \lambda \in$ ]0, $\left.\lambda^{\prime}\right]$, and we have

$$
y+\lambda(h+c) \in \text { cone }_{+}(F(A))+C_{+},
$$

which implies $y \in \operatorname{vcl}\left(\right.$ cone $\left._{+}(F(A))+C_{+}\right)$. Therefore, (15) holds. It follows from (14) and (15) that

$$
\begin{aligned}
\operatorname{vcl}(\operatorname{cone}(F(A)+C)) & =\operatorname{vcl}\left(\operatorname{cone}_{+}(F(A))+C_{+}\right) \\
& =\operatorname{vcl}\left(\operatorname{cone}_{+}\left(F(A)+C_{+}\right)\right) .
\end{aligned}
$$

Since $\operatorname{vcl}\left(\right.$ cone $\left._{+}\left(F(A)+C_{+}\right)\right)$is a convex set in $Y$, it follows from (18) that $\operatorname{vcl}(\operatorname{cone}(F(A)+C))$ is a convex set in $Y$. Therefore, $F$ is nearly $C$-subconvexlike on $A$.

Remark 13. If $Y$ is a locally convex space or a finite dimensional linear space, then the condition $\operatorname{icr}\left(\operatorname{cor}\left(\operatorname{cone}_{+}(F(A)+\right.\right.$ $\left.\left.\left.C_{+}\right)\right)\right) \neq \emptyset$ can be dropped. Thus, Theorem 12 generalizes Theorem 3.2 in [8] from locally convex spaces to linear spaces.

The following example shows that the converse of Theorem 12 is not true.

Example 14. Let $Y=\mathbb{R}^{2}, C=\left\{\left(y_{1}, y_{2}\right) \mid y_{1} \geq 0, y_{2}=0\right\}$, $C_{+}=\left\{\left(y_{1}, y_{2}\right) \mid y_{1}>0, y_{2}=0\right\}$, and $A=\{(1,0),(0,1)\}$. The set-valued map $F: A \rightrightarrows Y$ is defined as follows:

$$
\begin{aligned}
& F(1,0)=\left\{\left(y_{1}, y_{2}\right) \mid 1 \leq y_{1} \leq 2-y_{2}, y_{2}>0\right\}, \\
& F(0,1)=\left\{\left(y_{1}, y_{2}\right) \mid 1 \leq y_{1} \leq 2+y_{2}, y_{2}<0\right\} .
\end{aligned}
$$

It is easy to check that $\mathrm{icr}\left(\operatorname{cor}\left(\operatorname{cone}_{+}\left(F(A)+C_{+}\right)\right)\right) \neq \emptyset$. Moreover, $\operatorname{vcl}(\operatorname{cone}(F(A)+C))$ is a convex set in $Y$. Therefore, $F$ is nearly $C$-subconvexlike on $A$. However, cor $\left(\right.$ cone $_{+}(F(A)+$ $\left.C_{+}\right)$) is not a convex set in $Y$. Therefore, $F$ is not ic- $C_{+}-$ convexlike on $A$.

In Theorem 12, we do not suppose that $\operatorname{cor}(C) \neq \emptyset$. If $\operatorname{cor}(C) \neq \emptyset$, we have the following result.

Theorem 15. Let $F: A \rightrightarrows Y$ be a set-valued map on $A$. If $\operatorname{cor}(C) \neq \emptyset$, then $F$ is ic- $C_{+}$-convexlike on $A$ if and only if $F$ is nearly $C$-subconvexlike on $A$.

Proof. Necessity. Suppose that $F$ is ic- $C_{+}$-convexlike on $A$. Clearly,

$$
\begin{aligned}
\operatorname{icr}\left(\operatorname{cor}\left(\operatorname{cone}_{+}\left(F(A)+C_{+}\right)\right)\right) \\
\quad=\operatorname{icr}\left(\operatorname{cor}\left(\operatorname{cone}_{+}(F(A))+C_{+}\right)\right) .
\end{aligned}
$$

Since $\operatorname{cor}(C) \neq \emptyset, \operatorname{cor}\left(C_{+}\right) \neq \emptyset$. It follows from Lemma 10 that

$$
\begin{aligned}
\operatorname{cor}( & \left.\operatorname{cor}\left(\operatorname{cone}_{+}(F(A))+C_{+}\right)\right) \\
& =\operatorname{cor}\left(\text { cone }_{+}(F(A))+\operatorname{cor}\left(C_{+}\right)\right) \\
& =\operatorname{cone}_{+}(F(A))+\operatorname{cor}\left(C_{+}\right) \neq \emptyset,
\end{aligned}
$$

which implies that

$$
\operatorname{icr}\left(\operatorname{cor}\left(\operatorname{cone}_{+}(F(A))+C_{+}\right)\right) \neq \emptyset .
$$

By (20) and (22), we have $\operatorname{icr}\left(\operatorname{cor}\left(\right.\right.$ cone $\left.\left._{+}\left(F(A)+C_{+}\right)\right)\right) \neq \emptyset$. Since $F$ is ic- $C_{+}$-convexlike on $A$, it follows from Theorem 12 that $F$ is nearly $C$-subconvexlike on $A$.

Sufficiency. We suppose that $F$ is nearly $C$-subconvexlike on $A$. Since $\operatorname{cor}(C) \neq \emptyset$, it follows from Lemma 10 and (18) that

$$
\begin{aligned}
\operatorname{cor}\left(\operatorname{cone}_{+}\left(F(A)+C_{+}\right)\right) & =\operatorname{cor}\left(\operatorname{cone}_{+}(F(A))+C_{+}\right) \\
& =\operatorname{cor}\left(\operatorname{vcl}\left(\operatorname{cone}_{+}(F(A))+C_{+}\right)\right) \\
& =\operatorname{cor}\left(\operatorname{vcl}\left(\operatorname{cone}_{+}\left(F(A)+C_{+}\right)\right)\right) \\
& =\operatorname{cor}(\operatorname{vcl}(\operatorname{cone}(F(A)+C))) .
\end{aligned}
$$

Since $F$ is nearly $C$-subconvexlike on $A$, $\operatorname{cor}(\operatorname{vcl}(\operatorname{cone}(F(A)+$ $C)))$ is a convex set in $Y$. Hence, $\operatorname{cor}\left(\right.$ cone $\left._{+}\left(F(A)+C_{+}\right)\right)$is a convex set in $Y$.

Clearly,

$$
\begin{aligned}
\text { cone }_{+}\left(F(A)+C_{+}\right) & \subseteq \operatorname{vcl}\left(\operatorname{cone}_{+}\left(F(A)+C_{+}\right)\right) \\
& \subseteq \operatorname{vcl}\left(\operatorname{vcl}\left(\operatorname{cone}_{+}\left(F(A)+C_{+}\right)\right)\right) .
\end{aligned}
$$

Since $\operatorname{cor}(C) \neq \emptyset$ implies $\operatorname{cor}\left(\operatorname{cone}_{+}\left(F(A)+C_{+}\right)\right) \neq \emptyset$, $\operatorname{cor}\left(\operatorname{vcl}\left(\right.\right.$ cone $\left.\left._{+}\left(F(A)+C_{+}\right)\right)\right) \neq \emptyset$. By the near $C$-subconvexlikeness of $F$, it is easy to check that $\operatorname{vcl}\left(\left(\right.\right.$ cone $\left._{+}\left(F(A)+C_{+}\right)\right)$ is a convex set in $Y$. It follows from (c) of Lemma 9 that

$$
\begin{aligned}
\operatorname{vcl}\left(\operatorname{vcl}\left(\operatorname{cone}_{+}\left(F(A)+C_{+}\right)\right)\right) \\
\quad=\operatorname{vcl}\left(\operatorname{cor}\left(\operatorname{vcl}\left(\operatorname{cone}_{+}\left(F(A)+C_{+}\right)\right)\right)\right) .
\end{aligned}
$$


By Lemma 10, we have

$$
\begin{aligned}
& \operatorname{vcl}\left(\operatorname{cor}\left(\operatorname{vcl}\left(\text { cone }_{+}\left(F(A)+C_{+}\right)\right)\right)\right) \\
& \quad=\operatorname{vcl}\left(\operatorname{cor}\left(\operatorname{cone}_{+}\left(F(A)+C_{+}\right)\right)\right) .
\end{aligned}
$$

By (24), (25), and (26), we have cone $\left(F(A)+C_{+}\right) \subseteq$ $\operatorname{vcl}\left(\operatorname{cor}\left(\right.\right.$ cone $\left.\left._{+}\left(F(A)+C_{+}\right)\right)\right)$. Therefore, $F$ is ic- $C_{+}$-convexlike on $A$.

Remark 16. Theorem 15 generalizes Theorem 3.1 in [8] from locally convex spaces to linear spaces.

Remark 17. $\mathrm{Xu}$ and Song used Lemma 2.2 in [8] to prove Theorems 3.1 and 3.2 in [8]. However, in this paper, our methods are different from those in [8].

\section{Acknowledgments}

This work was supported by the National Nature Science Foundation of China (11271391 and 11171363), the Natural Science Foundation of Chongqing (CSTC 2011jjA00022 and CSTC 2011BA0030), and the Science and Technology Project of Chongqing Municipal Education Commission (KJ130830).

\section{References}

[1] H. W. Corley, "Existence and Lagrangian duality for maximizations of set-valued functions," Journal of Optimization Theory and Applications, vol. 54, no. 3, pp. 489-501, 1987.

[2] Z. F. Li, "Benson proper efficiency in the vector optimization of set-valued maps," Journal of Optimization Theory and Applications, vol. 98, no. 3, pp. 623-649, 1998.

[3] X. M. Yang, X. Q. Yang, and G. Y. Chen, "Theorems of the alternative and optimization with set-valued maps," Journal of Optimization Theory and Applications, vol. 107, no. 3, pp. 627640, 2000.

[4] X. M. Yang, D. Li, and S. Y. Wang, "Near-subconvexlikeness in vector optimization with set-valued functions," Journal of Optimization Theory and Applications, vol. 110, no. 2, pp. 413-427, 2001.

[5] P. H. Sach, "New generalized convexity notion for set-valued maps and application to vector optimization," Journal of Optimization Theory and Applications, vol. 125, no. 1, pp. 157-179, 2005.

[6] Z. Li, "The optimality conditions for vector optimization of setvalued maps," Journal of Mathematical Analysis and Applications, vol. 237, no. 2, pp. 413-424, 1999.

[7] E. Hernández, B. Jiménez, and V. Novo, "Weak and proper efficiency in set-valued optimization on real linear spaces," Journal of Convex Analysis, vol. 14, no. 2, pp. 275-296, 2007.

[8] Y. Xu and X. Song, "The relationship between ic-cone-convexness and nearly cone-subconvexlikeness," Applied Mathematics Letters, vol. 24, no. 9, pp. 1622-1624, 2011.

[9] J. V. Tiel, Convex Analysis, John Wiley \& Sons, New York, NY, USA, 1984.

[10] S. Z. Shi, Convex Analysis, Shanghai Science and Technology Press, Shanghai, China, 1990.
[11] M. Adán and V. Novo, "Weak efficiency in vector optimization using a closure of algebraic type under some coneconvexlikeness," European Journal of Operational Research, vol. 149, no. 3, pp. 641-653, 2003.

[12] H. W. Kuang and N. N. Yang, "A new kind of generalized convex set on linear spaces and its some applications," Journal of Southwest China Normal University, vol. 35, no. 4, pp. 1-5, 2010.

[13] M. Adán and V. Novo, "Proper efficiency in vector optimization on real linear spaces," Journal of Optimization Theory and Applications, vol. 121, no. 3, pp. 515-540, 2004. 


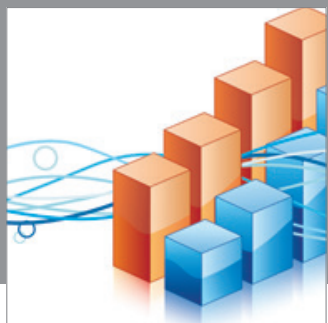

Advances in

Operations Research

mansans

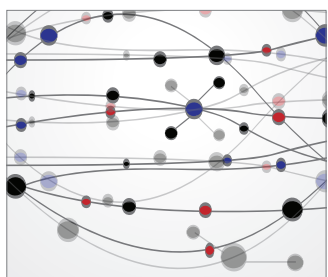

The Scientific World Journal
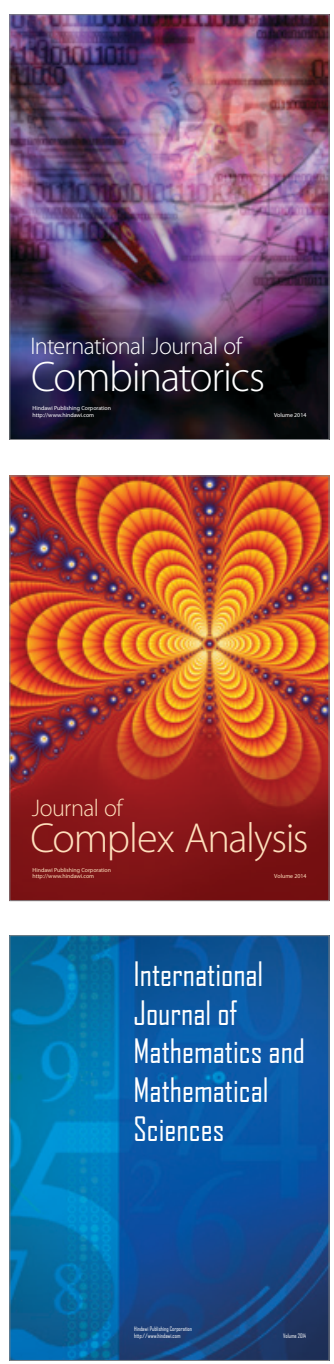
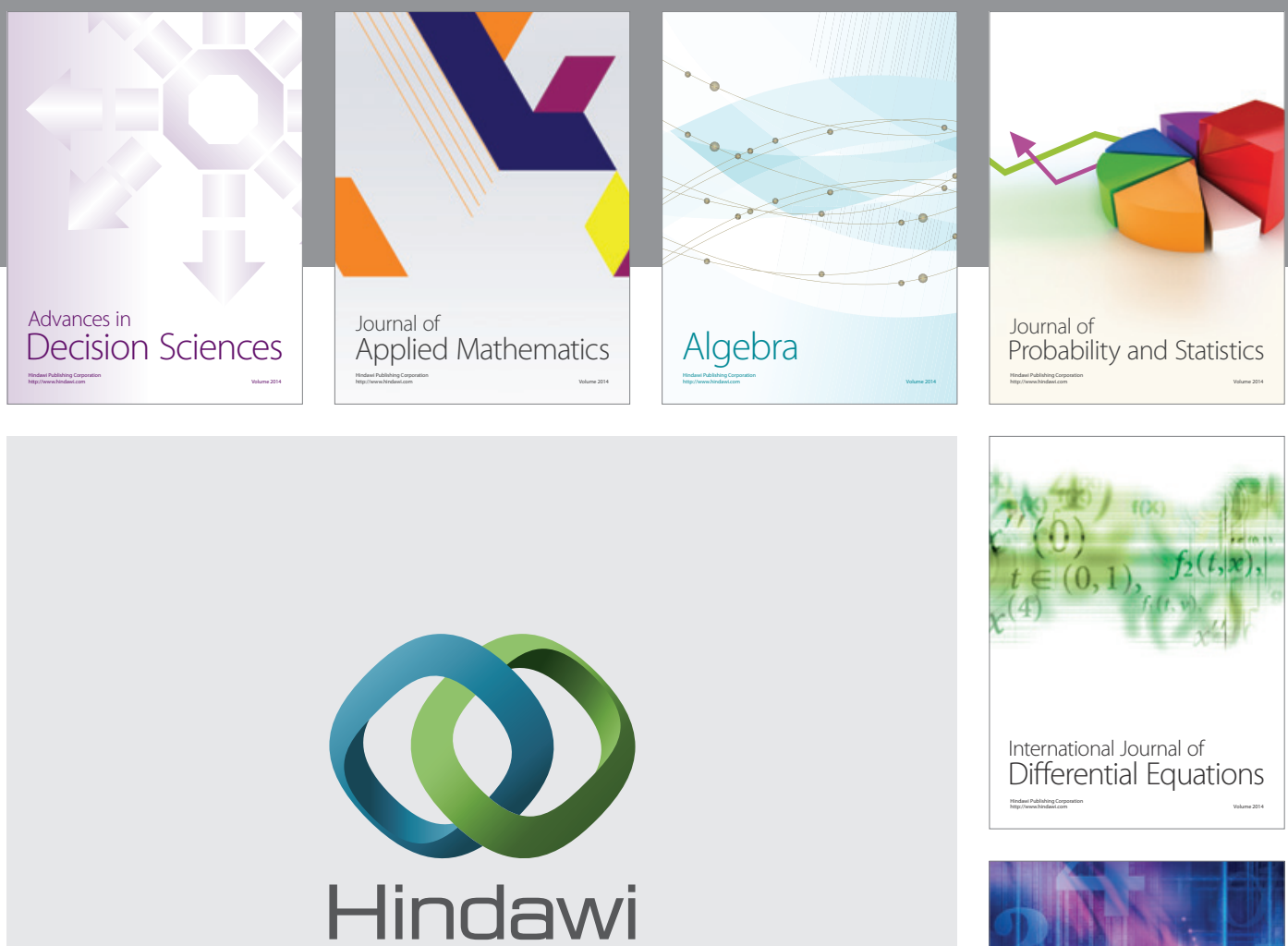

Submit your manuscripts at http://www.hindawi.com
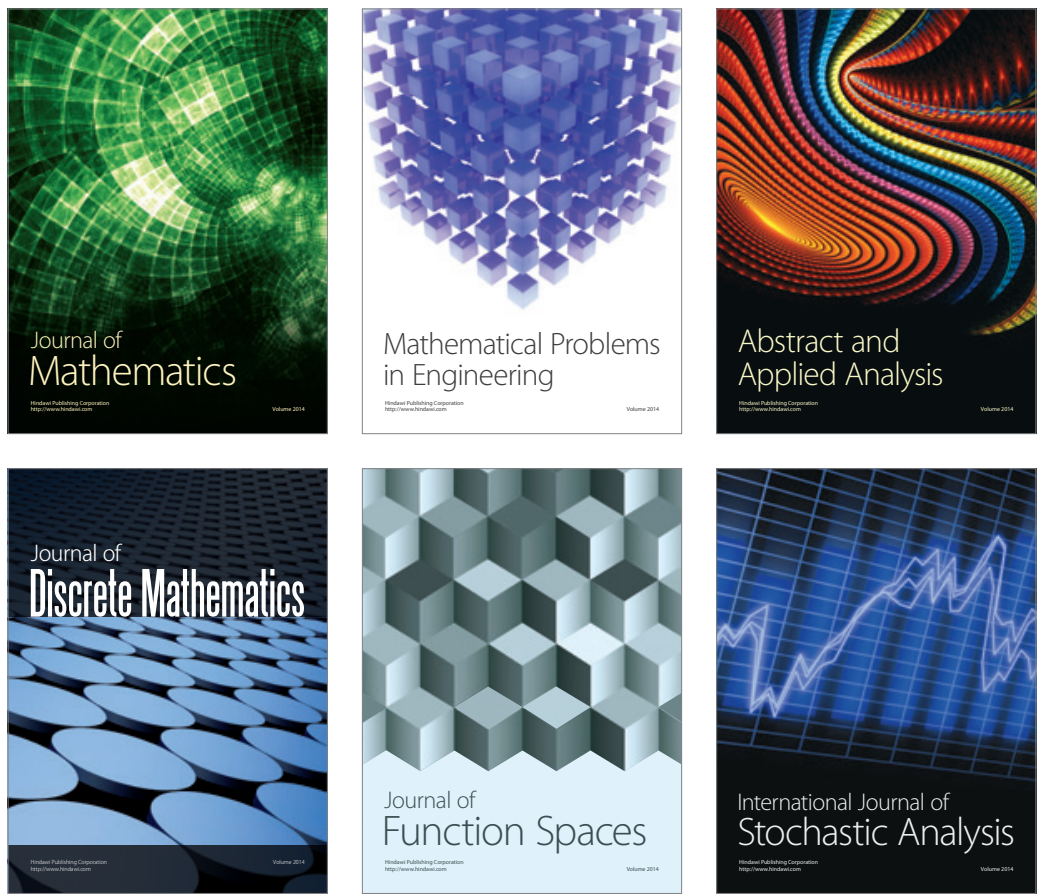

Journal of

Function Spaces

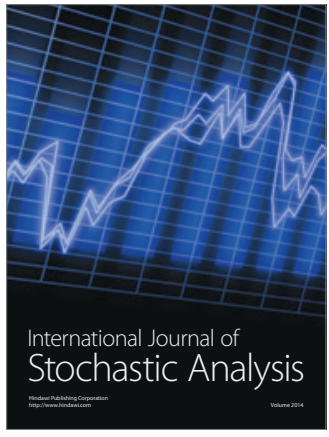

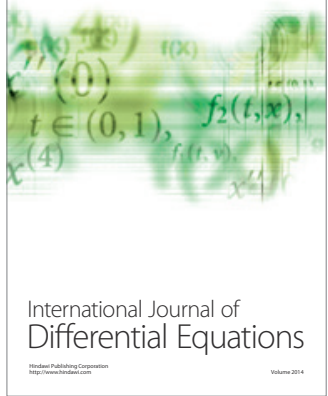
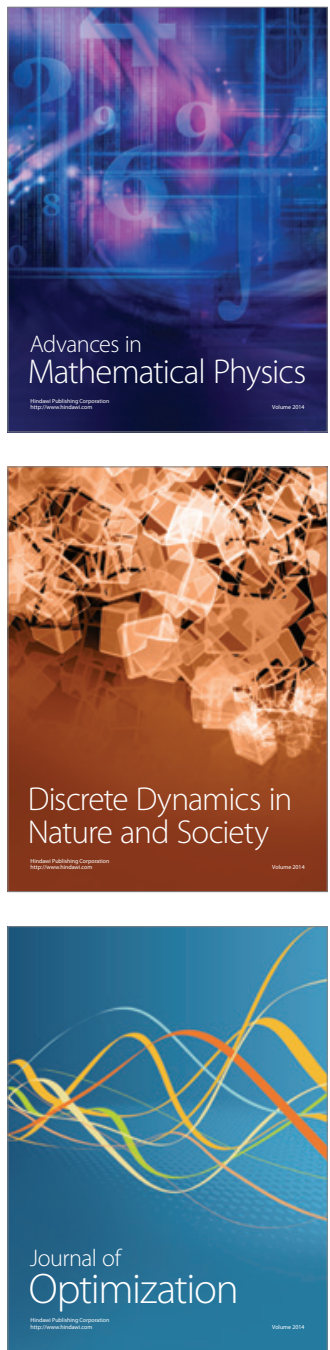